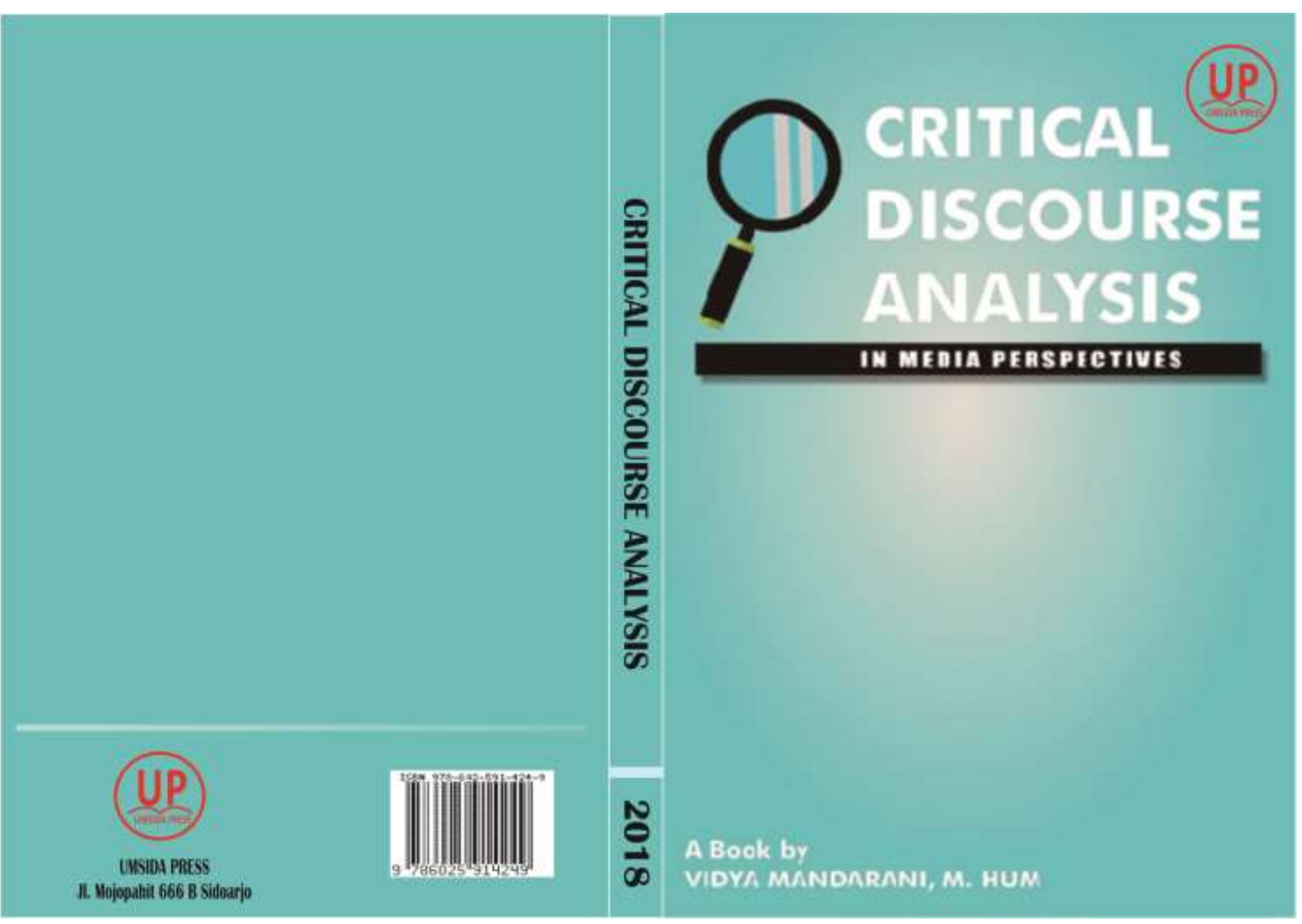




\section{Buku Ajar \\ Critical Discourse Analysis}

Disusun oleh:

Vidya Mandarani

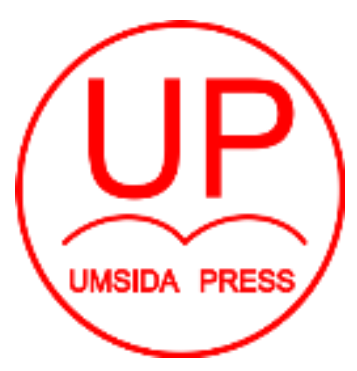

Diterbitkan oleh UMSIDA PRESS

Jl. Mojopahit 666 B Sidoarjo

ISBN: 978-602-5914-24-9

Copyright@2018.

Authors

All rights reserved 


\section{BUKU AJAR}

\section{CRITICAL DISCOURSE ANALYSIS}

\section{Penulis :}

Vidya Mandarani

\section{ISBN :}

978-602-5914-24-9

\section{Editor :}

Septi Budi Sartika, M.Pd

M. Tanzil Multazam, S.H., M.Kn.

\section{Copy Editor :}

Fika Megawati, S.Pd., M.Pd.

Design Sampul dan Tata Letak :

Mochamad Nashrullah, S.Pd

\section{Penerbit :}

UMSIDA Press

\section{Redaksi :}

Universitas Muhammadiyah Sidoarjo

Jl. Mojopahit No 666B

Sidoarjo, Jawa TImur

Cetakan pertama, Agustus 2018

(C) Hak cipta dilindungi undang-undang

Dilarang memperbanyak karya tulis ini dengan suatu apapun tanpa ijin tertulis dari penerbit. 


\section{PREFACE}

This book is written as the supplementary materials for teacher or student in Discourse Analysis subject. The materials consist of theories and practice of Critical Discourse Analysis (CDA). We also tried to enhance the students' critical thinking on the practice session; we name it Students Activities. From these activities, it is expected that the students are not only be able to comprehend the theoretical framework of critical discourse analysis, but also to improve students' ability to analyze language in media.

Finally, we realize that there are many drawbacks in this book; therefore, we would be very grateful and welcome for any corrections, comments, and criticism from all readers for our improvement. Thank you! 


\section{Table of Contents}

Cover

Preface $\quad$ i

Table of Contents ii

CHAPTER I DISCOURSE ANALYSIS

A. What is Discourse ........................................... 1

B. What is Discourse Analysis .............................. 4

C. Discourse Theories ............................................ 10

D. Relationship of Discourse Analysis with other Branches of Science ...................................................... 12

E. Types of Discourse .......................................... 19

F. Type of Discourse Based on Media Submission ... 23

G. Type of Discourse Based on Number of Speakers 26

\section{CHAPTER II CRITICAL DISCOURSE ANALYSIS}
A. Critical Discourse Analysis 28
B. Critical Discourse Analysis Procedure 39
C. Critical Discourse Analysis and Ideology 42 
D. Critical Discourse Analysis and Use of Language in Social Context 44

E. Language, Text, and Social Context in critical Discourse Analysis 46

\section{CHAPTER III MEDIA IN CRITICAL DISCOURSE ANALYSIS}
A. What is Media 50
B. Media in Discourse 52

\section{CHAPTER IV TEXT}
A. What is Text 59
B. Text and Discourse ........................................... 61
C. What is Textual Analysis in Discourse ................. 64

\section{CHAPTER V SOCIAL COGNITION}
A. What is Social Cognition 73
B. Discourse and Social Cognition 77

\section{CHAPTER VI SOCIAL CONTEXT}
A. What is Social Context
81
B. The Role of Context in Discourse Analysis 85
C. Concepts Relating to Context of Discourse 86 


\section{CHAPTER VII MEDIA AND IDEOLOGY}
A. Media
92
B. Ideology
93
C. Media and Ideology
98
D. Ideology and Discourse Analysis 100

\section{REFERENCES}

\section{ABOUT THE AUTHOR}




\section{CHAPTER I}

\section{DISCOURSE ANALYSIS}

\section{Basic Competence:}

Students are able to understand the definition and scope of discourse analysis

\section{A. What is Discourse}

Discourse is a sequence of sentences that are interconnected with each other and relate one proposition to another in the unity of the semantic meaning between the parts within a language construct. Discourse is also a complete and very complete language unity because every part of the discourse is related. According to Fatimah Djajasudarma (1994: 1), discourse is a series of interrelated sentences, can connect one proposition with another, forming a unity.

Discourse occupies the top hierarchy in the linguistic level because it is the highest and largest grammatical unit. And 
discourse can also be words, sentences, paragraphs, or essays that are very intact and larger, such as articles or books. Words that are often used in discourse are potential as sentences, not words that come out of context. Discourse relies heavily on the wholeness and originality of the elements of meaning and context that complement it.

A word or phrase may contain discourse, provided it qualifies as a discourse. Based on the above definition of a tech can be said discourse if it meets the requirements or characteristics - features as follows:

1. Topics

Topics are short statements, but contain a wider subject to be meaningful to the listener and reader.

2. Discloser topics

Speech participants or writers perform a specific act of speech as a form of expression.

3. Cohesion and Coherence

Cohesion is a cohesion between syntactic elements with one another including context in one discourse, while 
coherence forms linguistic records from a meaningful communication event.

4. Purpose (function)

A discourse can function informative, emotive, attitude, persuasive, and associative.

5. Regularity

Has a regularity of cohesion and regularity in logic that makes sense both in words, phrases, clauses, sentences, and in paragraphs.

6. Co-text, and Context

Context is a situation that encompasses the text, both the situation of the speaker, speaker, listener, time, topic, place, scene, event, mandate, code, and media. Co-text is, alignment, coordination, and text relations with other texts.

As the object of linguistic studies and research, discourse can be examined from various aspects. Discourse analysis examines the discourse both internal and external. From the internal point of view, discourse is examined from the types, 
structures, and relationships of parts of discourse; while from the external side, the discourse is studied in terms of the discourse's relevance with the speaker, the matters discussed and the talk partner.

Aspects contained in the discourse presents a very diverse study. Research on discourse is still a lot of work on internal language issues. Not many studies have explored discourse from an external perspective, such as social, literary, cultural, economic and others.

\section{B. What is Discourse Analysis}

Discourse is what makes us human. Encouraged by Fasold (2006: 500), he defined discourse as language use in specific context, but Discourse is the values, beliefs, and practices associated with the use of language. In principle, discourse analysis is the study of discourse, specifically focuses on how language is used in context. This study relates the forms of language to units of language use larger than sentences and to 
situation in which language is used. In the other words, it is often considered a crucial notion for understanding human communication. Sometimes, it is also defined as a study of the meaning that carried out when people do and use the language in specific context (Gee and Handford, 2012: 3). They added this study covers both pragmatics and study of text; how utterances and sentences pattern together to create meaning across multiple sentences or utterances. Furthermore, discourse analysis is popularly mentioned as DA and its role to study about complicated communicative event which represents a social context while the reception process. Shortly, DA is a study of investigating the meaning of language in use. It is supported by Brown and Yule (1983: 1), the function of DA is to analyze the use of language. It discusses the meaning based on the language use in specific context. Sobur (2015: 48) stated DA is a study of the various functions of language.

Discourse analysis is a branch of applied linguistics related to the evaluation of discourse in order to find communication patterns and other matters related to them that cannot be 
explained in grammar (Carter, 1993: 23). There are also those who say that discourse analysis is a discipline that seeks to study the use of real language in a communication. In this case discourse analysis emphasizes its study of the use of language in a social context, especially in the use of language between speakers where the language used can be accepted and understood by speakers even though the language is not formulated as the language rules as in standard grammar.

Renkema (1993: 34) says that to consider whether language units can be said as discourse or not, seven criteria are needed, namely:

1. Cohesion, which is the relationship generated at the time of interpretation of an element depends on other elements in the text. In other words, it involves the semantic relationship between elements in the text.

2. Coherent, which is a relationship based on something that comes from outside the text. Something that refers to the knowledge and experience possessed by speakers or speakers. 
3. Intellectuality, which involves the purpose and function of the language that participants have in communicating.

4. Acceptance, which refers to a series of sentences that are acceptable and can be understood by interlocutors (speakers / readers) in order to qualify as text.

5. Informality, namely that a text must contain new information and must be understood by the interlocutor

6. Nationality, which involves the situation of the place and the time the text was generated

7. Intellectuality, which refers to the connectedness of a discourse with other known discourses.

Of the seven criteria above, the most basic criteria in discourse are cohesion and coherence. In a discourse, the existence of context is very important role, because context can influence the meaning of words in a discourse, both oral and written. Discourse is actually a combination of text and context. In other words, a text will be called a discourse if there is a context. In this case, the speakers will understand a text if they 
also understand the context that accompanies the text. Context can be classified into three types, namely:

1. Situational context, which is the knowledge of speakers based on everything they see around them. In other words, the state of the physical situation visually regarding the place of interaction between speakers and speakers occurs.

2. Background knowledge context, which is the knowledge of speakers about interlocutors and about the world. Context of this basic knowledge consists of cultural knowledge and interpersonal knowledge. If interlocutors are from the same group, they will assume the same knowledge normally about everything they know. To share the context of interpersonal knowledge requires verbal interaction or prior experience.

3. Co-textual context or commonly known as co-text, which is the knowledge of speakers about what they have said.

In addition Saragih (2006) also classify the context into two groups, namely: 
1. Internal discourse context (cotext), in this case context linguistic or context language itself. This context refers to other linguistic units that accompany one unit that is being discussed. This context is inside and is part of the text in question.

2. External discourse context (social context), which is a context that refers to something written outside or spoken, which accompanies the language or text in the event of language use or social interaction. This context consists of three categories, namely: situational context, cultural context and ideological context.

In addition, DA is also known as discourse studies or textlinguistics (Van Dijk, 1988: 7). DA is nominated as new crossmultidisciplinary, because this study engages various fields. The target of DA is the social context practices. Social context means the context which includes social cognition (political or historical life) and social culture. This study focuses on both forms (verbal utterance and text), those have similar way to be analyzed. 
Media discourse related to communication activity which are conversation, stories, news report and so on. According to Van Dijk (1988: 1), there is exclusive media of discourse which is news, whether in the newspaper or on television. The news that is spoken form such dialogues must be transcribed into the written text. By discourse analysis, people are able to understand what is actually the meaning behind the content is served. Like the previous explanation, DA consists of several fields, one of them is Critical Discourse Analysis which is especially discuss about the way to construct the meaning behind the news text.

\section{Discourse Theories}

The theory of discourse by Ernesto Laclau and Chantal Mouffe is distancing discourse that focuses on constructing meaning in the social world, because the language is not stable and is never permanent, and therefore we must bare and really clean. While the theory of discourse by Teun A. van Dijk that discourse analysis is used to analyze the critical discourses, 
including politics, race, gender, social class, hegemony, and so on. Van Dijk saw a text consisting of multiple structures or levels each part support each other.

Discourse has two main elements, namely internal and external elements. The internal elements of discourse relate to the formal aspects of language, while the external elements of discourse relate to elements outside the language, such as the language's cultural background. The two elements form a cohesion in one complete and complete structure (Paina, 2010: 53).

The internal elements of discourse consist of units of words or sentences. What is meant by word unit is speech which is in the form of one word. To become a larger set of discourses, the unit of words or sentences will be related and joined (Mulyana, 2005: 9).

The external element of discourse is something that is also part of the discourse, but not explicitly, something that is outside the unit of lingual discourse. Its presence serves as a complement to the integrity of discourse. The external elements 
of the discourse consist of implicature, prefix, reference, and context (Paina, 2010: 54).

\section{Relationship of Discourse Analysis with other branches of Science}

1. Discourse Analysis with Phonology Abdul Chaer (2007: 102) explains that phonology is a linguistic field that studies, analyzes, and discusses the sound of language sounds. Discourse is a study that examines and studies the language used naturally, both in oral and written form. The relationship between phonology and discourse is as follows:

a. Phonology and discourse both use language as the object of the study, except that the difference is the phonology of studying the structure of language (especially the sound of language) while the analysis discourse language outside the structure / rules. Hierarchically, Phonology is the smallest level in Discourse. In examining the discourse, the theory of 
language sounds is necessary because Phonology is the foundation of other linguistic sciences.

b. Phonology and Discourse both examine the language in oral form, only that distinguish is the phonology does not study the language in the form of writing because the object is only the sounds of the language issued by the tools of human speech, while the discourse to examine the texts in the form of writing.

2. Discourse Analysis with Morphology

Wijana (2007: 1) explains that morphology is a branch of linguistics that studies the intricacies of morphemes and their incorporation to form lingual units called polymorphic words. The relationship between morphology and discourse is as follows:

a. Morphology and Discourse both use language as the object of the study. It's just that, similar to Phonology, morphology also examines the structure of language (especially the formation of 
words) while discourse analysis examines the language outside the structure / rules. Hierarchically, Morphology is the second smallest level in Discourse. In reviewing the discourse, the theory of word formation is needed because the discourse in the form of the manuscript is formed from the word-word arrangement that has meaning.

b. Morphology that learn the ins and outs of word formation is closely related to Discourse because in the Discourse must be appropriate in choosing words according to the intent to be conveyed by the Discourse.

3. Discourse Analysis with Syntax

Ramlan (1996: 21) explains that syntax is a branch of linguistics that deals with the intricacies of discourses, sentences, clauses, and phrases. While Kridalaksana in Tarigan (1984: 208) explains that discourse is the most complete set of languages, in the grammatical hierarchy 
the highest or the largest grammatical unit. This discourse is realized in the form of a complete discourse (novels, books, encyclopedia series, etc.) paragraphs, sentences or words that carry a complete message. The relationship between Syntax and Discourse is as follows:

a. Syntax and Discourse both use language as the object of the study. It's just that, similar to Phonology and morphology, Syntax also examines the structure of language (especially the formation of sentences) while discourse analysis examines the language outside the structure / rules. Hierarchy, Syntax is the third smallest level in Discourse.

b. The syntax that studies the ins and outs of sentence formation is closely related to Discourse because in reviewing, the theory of sentence formation is needed. A Discourse can be said to be good if the relationship between the sentences is cohesive and coherent. 
4. Discourse Analysis with Semantics

George in Tarigan (1964: 1), briefly and popularly explains that semantics is the study of meaning. Its relationship with Discourse is both semantic and Discourse equally examine the meaning of language as the object of study. The only difference is that Semantics examines the lexical meaning of language (linguistic meaning), whereas Discourse examines the contextual or implicature meaning of speech or texts.

5. Discourse Analysis with Pragmatics

Levinson (1983) in his book Pragmatics, gives some restrictions on pragmatics. Some of the limits put forward by Levinson include saying that pragmatics is the study of the relationships between language and the context underlying the explanation of the meaning of language. In this boundary means to understand the usage of the language we are required to understand also the context that accommodate the use of the language. Another limitation put forward by Levinson 
says that pragmatics is a study of the language-user's ability to associate sentences with the appropriate context for the sentences. The relationship between Pragmatics and Discourse is to equally examine the meaning of language caused by context.

6. Discourse Analysis with Philology

Philology is the language, culture, and history of the nation recorded in written material such as the relics of ancient linguistic texts, history and culture. The relationship between Philology and Discourse is equally examine the language in the form of text or script. The difference between the two lies in the theme or topic of the text or the text. Philology raises a topic that deals specifically with history while Discourse raises a more general topic of all social aspects of social life.

7. Discourse Analysis with Semiotics

Semiotics is a branch of language science that studies the meaning of the language generated from the signs 
of language in which the discourse is related is both discourse and semiotics alike studying the language. However, semiotics examine the meaning of language based on icons, symbols or indices while discourse studies the meaning of speech and utterances produced by the community.

8. Discourse Analysis with Psycholinguistics

Psycholinguistics is a study of how language is used and the acquisition of language by humans (Levelt, 1975). From this definition, there are two different aspects, namely the first acquisition of how a person, especially the children learn the language and the second is the use which means the use of language by normal parents. The relationship of Psycholinguistics with Discourse is in the formulation of discourses, topics or themes raised or utterances produced under the psychological condition of man. This Psychic Condition is one context that can support the researcher in interpreting an utterance. 
9. Discourse Analysis with Sociolinguistics

Wijana (2006: 7) explains that sociolinguistics as a linguistic branch views or locates the language position in relation to language users in society, because in human society life no longer as an individual, but as a social society. The relationship between Sociolinguistic and Discourse are both emphasize language in a context. The difference is the discourse of analyzing the speech (language) produced by the society while sociolinguistics focuses on the language user community.

\section{E. Types of Discourse}

Based on the type of discourse can be divided into five, namely the discourse of narration, description, exposition, argumentative, and persuasion.

1. Narrative Discourse

Narrative Discourse is one type of discourse that tells / tells a sequence of events in sequence of events. Thus 
this type of discourse does not intend to influence a person but rather tells of something that has been witnessed, heard and heard by the author (the author). Narratives can be fact or fiction (custom story). Narratives that are facts, such as biography and autobiography, while the form of fiction including short stories and novels.

2. Description Discourse

Discourse description is a discourse that describes things clearly and in detail. The description discourse aims to illustrate or give a picture of something so clearly that the reader as if he can see, hear, read or feel what is described. Therefore a good description is a description that comes with things that can stimulate the five senses. Examples such as flood conditions, atmosphere in the market and so forth. As writing other discourses in writing the description discourse there are steps, namely: 

a. Determining the topic of the description.
b. Formulate the purpose of creating a description.
c. Search, collect or select materials.
d. Make the outline.
e. Developing essays.

3. Exposition Discourse

Exposition Discourse is a discourse that explains or explains a discourse in detail (exposes) aims to be able to provide an information and can expand knowledge and knowledge for each reader. Discourse explaining or explaining (exposition) is usually used in a scientific work such as papers, scientific articles, for seminars, symposia, or upgrading. In the stages of writing an exposition, what must be done is to determine the object of observation, also determine the purpose of two exposition presentation patterns, by collecting material or data, composing a frame of essay, and also developing a framework into an essay. In the development of expository form exposition framework 
can be patterned presentation of the order of topics, the order of climax and anticlimactic.

\section{Argumentation Discourse}

Argumentation discourse is a discourse that aims to influence the reader to be able to accept ideas, opinions, or statements expressed by the author. To reinforce the idea or opinion, the author argumentation discourse includes supporting data. The goal, the reader becomes confident of the truth submitted by the author. In argumentation discourse, it is common to find some easily recognizable traits. These characteristics are:

a. There are statements, ideas, or opinions expressed by the author

b. There are reasons, data or facts to support

c. Justification based on data and facts submitted. 
5. Persuasion Discourse

Persuasion discourse is a discourse that contains an appeal or invitation to others to do something as expected by the author. Therefore it is usually accompanied by explanations and facts so as to convince and can affect the reader. The approach used in persuasion is an emotive approach that seeks to awaken and stimulate emotions, for example:
a. Group / class propaganda, campaign
b. Advertising in mass media
c. Leaflets

\section{F. Type of Discourse Based on Media Submission}

1. Oral Discourse

Oral discourse (spoken discourse) is a discourse delivered by spoken language or verbal media (Sumarlam et al, 2010: 16). Long before humans know letters, language has been used by humans. Humans use oral language in communicating. Spoken language became the main language in human life because it was 
first known and used by humans rather than written language. The weakness of oral discourse is the difficulty in repeating the discourse just as precisely as the first. The weakness of this discourse also causes oral discourse, as evidence, in the field of law has the weakest position than written discourse. With these descriptions can be made features of oral discourse as follows:

a. Oral discourse requires a high power to make interaction uninterrupted

b. Oral discourse is difficult to repeat, in the sense of repeating the same thing as the first speech

c. Oral discourse can be equipped with the movement of the limb to clarify the meaning in question

d. The oral discourse brings together its participants in the same situation and context.

e. Oral discourse is usually shorter than written discourse 
f. Oral discourse also involves a common ground of common knowledge, which is present in a family or group

g. Oral discourse often involves its participants directly.

\section{Written Discourse}

Written discourse is a discourse delivered with written language or written media (Sumarlam et al, 2010: 16). Written discourse began to be known after found the letters, letters are made to replace the role of language sounds so that people usually say that the letter is the symbol of sound. The letters were studied by humans and then used to convey information to others who lived far apart. Despite many long written discourses, there are also short written discourse, such discourse is often found in advertisements, in railway stations, in supermarkets, and on the street. 


\section{G. Type of Discourse Based on Number of Speakers}

1. Monologue Discourse

Monologue discourse is a discourse delivered by a single person without involving others to participate directly. Generally, monologue discourse does not want and does not provide time allocation to the response of listeners or readers. The discourse of monologues is unidirectional and includes non-interactive communication.

2. Dialog Discourse

Dialog discourse is a conversation made by two people directly. Discourse dialogue is two-way, and each participant actively participate in communication, so called interactive communication (interactive communication). Discourse dialogue occurs as in the event of discussion, deliberation, telephone conversation, $Q \& A$, and drama texts. 
3. Polilog Discourse

Polilog discourse is a conversation or conversation involving the participants of the conversation of more than two speakers. Participants involved in the conversation all play an active and direct role in communication. Polilogic discourse occurs as in deliberation, discussion, or debate, and drama texts.

\section{Students Activities:}

1. Discourse analysis is the study relates the forms of language to units of language use larger than sentences and to situation in which language is used. Give clear explanation about above statement.

2. Explain why there is Relationship of Discourse Analysis with other branches in Linguistics field?

3. Based on the type of discourse can be divided into five, namely the discourse of narration, description, exposition, argumentative, and persuasion. Give explanation of each type! 
CAAPTER II

CRITICAL DISCOURSE ANALYSIS

\section{Basic Competence:}

Students are able to understand the definition and scope of critical discourse analysis

\section{A. Critical Discourse Analysis}

Critical discourse analysis (CDA) is a type of discourse analytical research and studies the way social power abuse, dominance, and resisted by the text and talk in the political and social context.

Van Dijk gives the definition of the CDA as follows, critical discourse analysis (CDA) is a kind of discourse analytical research that primarily learn how the way social power abuse, inequality and dominance are applied, reproduced, and resisted by text and talk in the political and social context. It means that critical discourse analysts critical discourse analysts reject social 
inequality, take explicit position, and thus to understand and expose. It. According to Van Dijk (2006:252), critical discourse analysis is primarily interested in and motivated by the endeavor to understand pressing social issues. Van dijk, also states that in critical discourse analysis more focus on the role of discourse in the challenge and the reproduction of dominance. Dominance here refers to the power of social groups, elite, institutions in social inequality, it is include the political, cultural, gender, ethnic and class.

Furthermore, Van dijk states that a critical research in discourse analysis needs to arrange a number of requirements to get the effectively relize its aims, those are:

- The research of CDA must be "better" than another research in order to be accepted.

- CDA focuses on political issues and social problems, rather than focuses on fashions an paradigms.

- Multidisciplinary on CDA is empirically adequate a critical analysis of social problems. 
- CDA tries to explain in terms of social interaction properties and especially the social structure.

- Be specific, CDA focuses on ways of discourse structures enact, legimate, confirm, reproduce, or challenge relations of dominane and power in the society.

Van Dijk states that critical discourse analysis focus on the dominance of power by social group. According to Fairclough (2003:2), states that Critical Discourse Analysis or CDA is based on the assumption of language that is also as part of social life, interconnected of dialectically with other social life elements, so social analysis and research has to take account of language. Furthermore, Critical discourse analysis is the study of how discourse brings the critical tradition of the analysis of social into the study of language, and the contribution of critical social analysis in a particular focus on discourse itself and on the relations between discourse and the other social elements, such as, ideologies, power relations, social identities, institutions, and 
so forth. Fairclough and Wodak also have same opinion and summarize toward CDA, the main tenets of CDA as follows:

1. CDA tends to addresses the social problems.

2. The relations of power are discursive.

3. Discourse establishes culture and society.

4. Discourse also does the ideological work.

5. Discourse is historical.

6. There is mediated link between text and society.

7. Discourse analysis is explanatory and interpretative.

8. Discourse is social action.

In addition, Fairclough (2003: 3) states that the role of CDA is to identify discourse which reconstruct social life through analysis the specific part of linguistic such as semiotic and features of text. In short, Fairclough classified CDA into three dimensions: text, discourse practice and sociocultural practice. Whereas, Van Dijk's dimensions are textual analysis, social cognition, and socio-cultural context.

In a brief, CDA is the study of how to examine the way forms of power abuse, dominance and inequality are expressed in a 
whole text and talk. This discipline pay more attention to analyze the structures, strategies or the other properties of text or communicative interaction in reproducing power relations.

According to Fairclough and Wodak (1997: 258) critical discourse analysis examines further the use of language in speech and as a form of social practice. Discourse analysis model of Norman Fairclough (Eriyanto, 2001: 286) divides the critical discourse analysis into three dimensions, one of them is textual dimension or microstructural. Each text in a media has three functions, namely representation, relation, and identity. The function of representation is related to the style used to present the social reality into written form. Text analysis involves linguistic analysis which include the analysis of vocabulary and semantics, and grammar of the sentence. It can be called a linguistic analysis. There are several things which can be analyzed to understand the textual meaning. First, cohesion and coherence; this analysis aims to know the clauses formed into sentences, then sentences formed into a larger unit. It can be seen through the use of lexical repetitions, synonyms, antonyms, 
pronouns, conjunctions, and others. Second, grammar; this analysis focuses on the transitivity, themes, and modality. The transitivity is analyzed to know the use of verb that construct a clause both active and passive clause. The use of active and passive clause has an effect in the subject, affirmation, or others. Third, an analysis of the key words are selected and used in the text. Vocabulary selection is closely related to the event, a person, group, or specific activities. This vocabulary will be helpful in determining the analysis because it deals with the question of how the language is used and constructed.

Analysis of the theme aims to identify the thematic structure of a text in the media. In this analysis, the recurring theme and the background appearance will be analyzed. Analyzing a part in the sentence that is more dominant than others. While the modality is used to indicate the level of knowledge or level of utterance (Badara, 2012). Fairclough saw modalities as forming social relationship that are able to interpret the attitude and power in the society. 
Critical discourse analysis uses the language in the text to be analyzed. In this case language is analyzed not merely from the aspect of language, but also connects language with its context, including the practice of power. Fairclough and Wodak (1997: 137) assert that critical discourse analysis discusses discourse (the use of language in speech and writing) as a form of social practice that may display ideological effects, produce and reproduce unequal power relationships between social classes, women, and majority and minority groups. Through discourse, inequality in social life is seen as a common sense, a natural or natural. The following presents important characteristics of critical discourse analysis from Fairclough and Wodak.

\section{Action}

Discourse is understood as an action, associating it as a form of interaction, rather than being placed in an enclosed space and internally. The assumption, people speak, write, and use language is to interact with others. Consequently discourse should be viewed as, first, discourse is seen as something of purpose (influencing, 
arguing, persuading, supporting, reacting, etc.; second, discourse is conceived as something expressed consciously or controlled, not something out of control or expressed in out of consciousness.

\section{Context}

Critical discourse analysis considers context, such as setting, situation, event, and condition where discourse is produced, understood, and analyzed. Context includes all situations and things that are outside the text and affect the language, such as participants in the language, the situation in which the text is produced, and also the text is conveyed through what medium. However, not all contexts are included in the analysis, only relevant and in many cases influencing the production and interpretation of the texts analyzed.

3. Historical

Placing discourse in a particular social context means that discourse is produced in a certain context and can 
be understood without including the context that accompanies it. One of the most important aspects of understanding the text is to place the discourse in a particular historical context. How was the political situation then, and the atmosphere at that time.

\section{Power}

Any discourse in the form of text, conversation or anything, is not regarded as natural, natural and neutral but a form of power struggle. The concept of power is one of the key relations between discourse and society. Like power in the discourse of sexism, white power against blacks in discourses on racism, corporate power is dominated by upper-class businessmen to their subordinates, and so on. Critical discourse analysis does not limit the details of the text or discourse structure, but also connects with certain social, political, economic, and cultural forces and conditions. Power in relation to discourse, to see what is called control. Control here is not necessarily physical and direct, but 
also mental and psychological control. The form of discourse control can be control over the context (who should be covered) or control over the discourse structure (how the headline should be displayed).

5. Ideology

Text, conversation and others are a particular form of ideology. Critical discourse analysis seeks to see how the ideology of certain groups play a role in making discourse. The classical theories of ideology explain that ideology is built by dominant groups with the aim of reproducing and sabotaging their dominance. One of the main strategies is to attack the audience awareness so that the ideology is taken for granted. Important ideological implications according to van Dijk (1997: 25) are (1) ideologies inherently social, non-personal or individual, thus creating cohesion and group coordination functions; (2) ideology is used internally within a community so as to construct a group's selfidentity. 
Critical discourse analysis provides theories and methods that can be used to conduct empirical studies of the relationships between discourse and social and cultural development in different social domains (Jorgensen and Philips, 2007: 114). The purpose of critical discourse analysis is to explain the linguistic dimensions of social and cultural phenomena and the process of change in modernity (Jorgensen and Philips, 2007: 116).

Thus, critical discourse analysis is a theory for conducting empirical studies of the relationships between discourse and socio-cultural development. To analyze the discourse, one of which can be seen in the linguistic area by paying attention to the sentences contained in the text (novel) can use the theory of critical discourse analysis. Critical discourse analysis theory has several characteristics and approaches.

The context of discourse is shaped by the various elements, namely situations, speakers, listeners, time, place, scene, topic, event, form of message, code, channel (Alwi 1998: 421). Discourse contexts include: 
a. The physical context that covers where the language is used in a community, the object presented in the event of the communication and the action or behavior rather than the role in the communication event.

b. Epistemic context, or background of knowledge that is equally known by both speakers and listeners.

c. Linguistic context, which consists of sentences or utterances that precede a particular sentence or speech in a communication event.

d. Social context, is social relations and setting settings that complement the relationship between the speaker and the listener.

\section{B. Critical Discourse Analysis Procedure}

Discourse is the use of language that is understood as social praxis (Fairclough, 1995: 135). Discourse - and many examples of certain discursive praxis - in Fairclough's view must be seen simultaneously as (i) language texts, either oral or written, (ii) praxis of discourse, namely production and interpretation of 
texts, and (iii) sociocultural praxis, namely changes in society, institutions, culture, etc. that determine the form and meaning of a discourse.

The three elements according to Fairclough are called "discourse dimensions". Analyzing discourse critically is essentially analyzing these three dimensions of discourse integrally. These three dimensions are as a whole that cannot be separated from one another.

1. Language Text Analysis.

In a critical view, the text is constructed from a number of linguistic tools, which conceal ideology and power. In its application, Critical Discourse Analysis uses much of the linguistic tools suggested in Halliday's functionalsystemic linguistics (1985; 1994) and Fowler's (1986) critical linguistics to provide for the possession of linguistic structures in the language text. In this stage, the analysis consists of (i) vocabulary, (ii) grammar, and (iii) text structure. 
2. Praxis Analysis of Discipline

Praxis of discourse is related to the production and interpretation of discursive processes. The second stage analysis of Critical Discourse Analysis is in the form of interpreting (to interpret) the relation between production and interpretation of discursive processes. Two things that become material are (i) text interpretation, and (ii) interpretation of context. In the interpretation of the text, there are four levels of interpretation domain, namely (i) birth form speech, (ii) speech meaning, (iii) local coherence, (iv) text structure and points. In the interpretation of context, there are two levels of interpretation, namely (i) the situational context, and (ii) the context between the contexts.

3. Sociocultural Praxis Analysis

The relationship between text and social structure is mediated by the social context of the discourse. Discourse will become real, operate socially, as part of the processes of institutional struggle and society. The third stage analysis of Critical Discourse Analysis is in the 
form of explaining the relationship of heterogeneous textual features along with the complexity of the discourse process with the process of sociocultural change, both community, institutional and cultural changes. According to Fairclough (1989: 163) the purpose of the explanatory stage is "photographing" discourse as part of the social process, as social praxis, which shows how the discourse is determined by any social and reproductive structure that influences discourse that cumulatively uses, sustains, or changes structure the structure.

\section{Critical Discourse Analysis and Ideology}

Literally, ideology means the science of ideas according to the times, the development of science, and knowledge. Ideological boundaries are a system of values or ideas owned by certain groups or layers of society, including processes that are general in the production of meanings and ideas. Critical Discourse Analysis studies about the dominance of an ideology 
as well as injustice run and operated through discourse. Fairclough argues that Critical Discourse Analysis sees discourse as a form and social practice. Discourse practices display ideological effects.

Ideology is a central concept in Critical Discourse Analysis, for example literary discourse is a form of ideology or reflection of a particular ideology. This ideology is constructed by the dominant group with the aim of reproducing and legitimizing their domination. One strategy is to create awareness of the audience, which the dominance is taken for granted. Ideology in this case is inherently social and Critical Discourse Analysis sees discourse as a form of social practice.

A critical study of the language highlights how conventions and language practices relate to power relations and ideological processes that are often not realized by society. Some of the main ideas about critical study of language are:

1. Discourse is formed by society

2. Discourse helps shape and change knowledge and objects, social relations, and social identity 
3. Discourse is shaped by power relations and associated with ideology

4. Establishment of discourse marks a push-pull power (power struggles)

5. Discourse examines how society and discourse form each other

\section{Critical Discourse Analysis and Use of Language in Social Context}

Discourse analysts are increasingly aware of the varied choice and breadth of objects of linguistic research, ie the actual use of language in its social context. The psychological and intellectual paradigm doubts its accuracy in analyzing the discourse laden with features of broad social context, such as gender, power, status, ethnicity, role, and institutional setting.

Discourse is understood as units and speech forms of interactions that are part of everyday linguistic behavior, but can appear equally in the institutional environment. Discourse 
requires the shared presence of speakers and listeners (face-toface interactions), but can be reduced towards temporal shared presence (e.g. in the telephone).

In the context of linguistic behavior theory, it is important to determine the "text", the linguistic behavior that the material made in the text is separated from the general speech situation which is only as the reader's receptive behavior, the basis generally understood in the systematic sense, not the historical meaning. In text, speech behavior has a quality of knowledge in serving the transmission as well as stored for subsequent use in a constitutive written form for the use of everyday terms. Thus, the text is seen as a linguistic phenomenon that is independent and separate from the speech situation. Meanwhile, discourse is a text that is in a speech situation according to van Dijk discourse is the text "in context". For the purpose of discourse analysis it must be viewed from three dimensions simultaneously (Fairclough, 1995: 98), that is language texts, discourse praxis, socio-cultural praxis. Analyzing a discourse critically is essentially 
analyzing the three dimensions of the discourse as a dialectical application.

\section{E. Language, Text, and Social Context in Critical Discourse}

\section{Analysis}

a. Language as Social Semiotics

Language as one of a number of systems of meaning, such as traditions, livelihoods, and systems of courtesy, together form human culture. In this social process, the reality construct cannot be separated from the construct of the semantic system, where the reality is done. At a very concrete level, language contains no words, clauses or sentences, but language contains text or discourse, ie the exchange of meaning. In an interpersonal context, the context in which that meaning is maintained is not at all without social value. Through the act of everyday meaning, society plays a social structure, affirms the status and role it has, and sets and defines a system of values and knowledge. 
b. Text

The text relates to what is actually done, interpreted, and said by the community in real situations. Halliday (1978: 40) states that text is a semantic choice of social context data, which is a way of expressing meaning through spoken or written language. All living languages that take a certain part in the context of a situation can be called text. In this case there are four notes on the text that need to be put forward as follows:

1. Text is essentially a semantic unit

2. Text can project meaning at a higher level

3. The text is essentially a socio-semantic process

4. Situation is the determinant of the text

c. Situation Context

Halliday mentions that the situation is the environment in which the text comes to life. To understand the text as well as necessary an understanding of the context of the situation and cultural context. In Halliday's view, the context of the situation consists of three elements, namely 
the field of discourse, the involvement of discourse, and the means of discourse. Jones views the field of discourse as the context of the situation that refers to the social activities that are taking place and the institutional setting in which the material units appear. In the field of discourse there are three things that need to be revealed, namely the realm of experience, short-term goals, and long-term goals. There are three things that need to be revealed in the involvement of discourse, namely the role of agents or communities, social status, and social distance. There are three discourses on social reality:

1. Discourse is part of social activity.

2. Representation, which is a process of social practices.

3. Discourse illustrates how something happens in constitutional identities. 


\section{Students Activities:}

1. Critical discourse analysis seeks to see how the ideology of certain groups play a role in making discourse. How is the discourse seeks the ideology of the discourse?

2. Critical Discourse Analysis is the study of how to examine the way forms of power abuse, dominance and inequality are expressed in a whole text and talk. Give clear explanation about the statement.

3. Any discourse in the form of text, conversation or anything, is not regarded as natural, natural and neutral but a form of power struggle. Why do the powe struggle become the part of discourse? 
CHAPTER III

MEDIA IN CRITICAL DISCOURSE ANALYSIS

\section{Basic Competence:}

Students are able to understand the relation of Media in Critical Discourse Analysis

\section{A. What is Media}

Media is all forms and channels are used to convey information or messages. The word media comes from the Latin word, is the plural form of the word "medium". Literally the word means "intermediary" or "introduction", namely the intermediary of the message source (a source) with the recipient of the message receiver. Therefore, in another sense, the media is a tool or means used to convey messages from communicators to the public.

According to Miarso, media is anything that can be used to channel messages that can stimulate students' thoughts, 
feelings, attention, and willingness to learn. Meanwhile, based on the National Education Association (NEA), media is a means of communication in print and audio visual form, including hardware technology. In general, media types can be divided into:

1. Visual Media

Visual media is a media that can be seen, read and touched. This media relies on the sense of sight and touch. Various types of media is very easy to obtain. Examples of media that are very numerous and easy to obtain or make yourself are photo media, pictures, comics, sticky images, posters, magazines, books, miniatures, props and so on.

\section{Audio Media}

Audio media is the only audible medium, using the ear senses as the channel. For example: sound, music and songs, musical instruments, radio broadcasts and sound cassettes or CDs and so on. 


\section{Audio Visual Media}

Audio visual media are media that can be heard and seen simultaneously. This medium moves the senses of hearing and sight simultaneously. For example, media drama, performances, film, television and media are now flourishing, the VCD. The internet is included in the form of audio visual media, but it is more complete and unites all types of media formats, called Multimedia because various formats exist on the internet.

\section{B. Media in Discourse}

Media present in the public space is not without interest. There is a capital power that can drag the media towards business fatalism and deny its function as a guardian pillar of democracy. Therefore, in looking at a media, it is important to examine what is behind the news that is displayed either in print or electronic media. Media analysis becomes important to test what interests are behind a story. 
In a media, at least two of the most important things, namely facts, are presented in the form of news even though in their reporting sometimes subjectivity is high. Next is the opinion, this is displayed in the form of caricatures, headlines, letters of readers, columns, letters of readers and articles. In analyzing the mass media there are three that are often carried out by many media analysts, namely:

1. Empirical positivism

According to them, discourse analysis describes the rules of sentence, language, and mutual understanding. Discourse is measured by the consideration of truth or untruth according to syntax and semantics (the point of attention is based on whether or not the language is grammatically). This analysis is called "Content Analysis" (quantitative).

2. Constructivism

It can also be called discourse analysis as an analysis to uncover certain intentions and meanings. Discourse is 
an attempt to reveal the hidden intentions of the subject that poses a question. Disclosure is done by placing itself in the speaker's position with an interpretation following the structure of meaning from the speaker. This analysis is commonly called "Framing Analysis" (frame).

\section{Critical paradigm}

Correct constructivist views that are insensitive to the production process and reproduction of meaning. Language is understood as a representation that plays a role in forming certain subjects, specific discourse themes, and strategies in them. Language is always involved in power relations.

Thus, through the meaning of the media and discourse means the meaning of media content in the form of words, the expression of ideas conveyed by the media as a means of mass communication to the community. Thus, the physical form of discourse are the contexts that are highlighted and discussed in 
the text of the media. For example, in the television media there is news that contains the discussion about the Blasphemy of Religion, here the media actors compile how to influence public opinion about the case through the texts and symbols contained therein. The goal is to provide information to others.

An example of someone updating only pictorial coffee and home along with emoji cloud overcast on social media accounts, of course for the layman would be difficult to understand. However, for the perpetrator of communication would have two meanings. First, it has the meaning that he is drinking coffee at home when the clouds are overcast. Second, it has a meaning that he wants to drink coffee in a place to copy after the rain comes. Well, here is the meaning of the text submitted by him to others through new media in the form of symbols. Because it is the part that seeks to provide an explanation of the meaning hidden in the media text, in this case is the new media.

Then, with the discussion about Media and Discourse here will certainly have an impact on the community to better understand the meaning of news coverage in the media, 
especially on new media. So that no longer common sense in understanding the medium. Because, the character of the discourse itself, including:

1. It is more qualitative, therefore will discuss and try to understand the hidden messages

2. Then the focus is on the question "how it is said".

3. Do not intend to generalize. Since events are always unique, it cannot be treated the same procedure for different issues and cases (Eriyanto, 2001: 337-341).

4. In addition, there are also elements of the discourse structure to the media developed by Van Dijk, including:

a. Thematic, the message's core Schematic, namely the context of the presentation of the message by emphasizing the title \& terrace news and stories.

b. Semantics, the particular meaning that is hidden from the message to direct the particular direction of the event.

c. Syntax, the ins and outs of the discourse 
d. Stylistic, the style of language that the author uses to convey his point.

e. Rhetorical, which is the style that is expressed when one speaks or writes.

In this discussion it is very clear that media and discourse are closely related. Although at this time it appears that the name of new media is very used once to convey certain intentions through messages presented through text. And the common people especially us communicators must know, understand, \& try to give an explanation of the hidden meaning of the message conveyed by the media. In order to provide information to ordinary people with the aim of avoiding the purpose of the message maker leads to one position of the event. This is what is now intensively conducted by media players. 


\section{Students Activities:}

1. Media experts are all the means and channels used to convey information or messages. Please explain the relationship between the media and discourse!

2. Find one of the news media, then analyze the discourse of the media

3. Then please connect the news to the character of of the discourse 


\section{Basic Competence:}

Students are able to analyze the text use critical discourse analysis theory

\section{A. What is Text}

Text is all of language form. We can find text in all of communication such as speech, debate, conversation, and daily taking. Text can be said as the representation of discourse. Besides, there is also spoken text, but when we analyze them we will be looking at them in written form. Brown and Yule (1983:6), text as technical term to refer to the verbal record of a communicative act whether spoken or written.

Generally, text is a unit of analysis whether it is written or spoken form. It is written from a particular viewpoint. It is as printed-record which popular used in literature field. Minimally 
text consists of the words and presents in the same order. According to Fairclough (2003: 3), texts are thing that is written and printed texts, such as transcripts of spoken communication, newspaper articles, or shopping list. An understanding of text reaches beyond the production of printed material in a large number of printed forms. Especially texts of mass media have chosen in selecting text forms: content, language and specific views to create readers assumption.

Frequently, texts in mass media uses stereotypes in order to deliver certain messages. Indirectly, it also used to advertise their product. Fortunately, in CDA, it also deals with the position of the writer that the readers are able to explain the structures and function of the text in headlines or news report in mass media (Van Dijk, 1988: 9). In order to understand the structure of news report, it only can be done by do depth-analysis. After that, it may be useful to differentiate between cognitive processing or social practices of textual communication and the structures of media texts themselves. 
In addition, a text must be coherent as well as cohesive to the reader although in many interpretations of them.

\section{B. Text and Discourse}

The terms text and discourse are two terms that are often used when people analyze language usage. However, its relatively broad use does not make the term text and discourse have a clear understanding. Since both terms have sounded so familiar, they both seem to have been clearly understood. It is not surprising that the two terms have never been specifically addressed and clearly defined.

This has shown that the terms text and discourse have been used overlap. At one time, the two are distinguished, but when the other is both equated. In addition to the use of overlapping terms of text and discourse terms, the term discourse is defined as a structurally lingual product. This structural definition of text cannot cover all the lingual facts that are encountered in daily life. 
This lack of clarity in the definition of text and discourse ultimately has direct implications for the obscurity of the object, method, and purpose of the study. There are two types of blur in this case. The first blurring relates to what the object of discourse analysis studies is, how the method of analysis is, and what is the purpose of the analysis. The second blurring is related to the emergence of the term textual discourse analysis and contextual discourse analysis.

According to Van Dijk in analyzing discourse, it is not enough only based on text analysis, because the text is only the result of a production practice. Understanding of text production will ultimately gain knowledge of why the text can be. Van Dijk also saw how social structure, domination, power groups that exist in society, how cognition or mind and consciousness that shape and influence certain texts (Eriyanto, 2011: 223). According to Eriyanto in his book entitled Discourse Analysis, it is mentioned that, text according to van Dijk consists of above several complementary structures / levels that comprise the structure. First, the macro structure is the global / general meaning of the 
text. Second, the superstructure is the framework of a text, such as the introduction, content, closing and conclusion. Third, the meaning of a text that can be observed from the choice of words, sentences, and styles used in a text.

The peculiarities of Van Dijk in viewing the news structure in newspapers focused on the thematic structures and the newspaper schemata. Thematic elements refer to the general description of a text. Also called the core idea, summary, or the main one of a text. The text also has a scheme or groove from the introduction to the end.

Text is compiled and sorted so that it forms a unity of meaning. The news scheme generally hypothetically has a unity of meaning that is discourse by the mass media which is generally characterized by the title and lead and story elements, namely the content of the news as a whole. Then later at the news level, they see and analyze what is explicitly discouraged by the mass media. For example, in political or legal reporting, there is usually a political perspective raised by the mass media. 
The news discourse here is not only understood in terms of a number of structures but also part of a complex communication process. The key point in understanding the production of news is to examine the process of forming text.

\section{What is Textual Analysis in Discourse}

Textual analysis is a way for researchers to gather information on how to make other humans understand the world. It's a methodology, the collection process, for researchers who want to understand the ways in which members of different cultures. According to Fairclough (2003:9) textual analysis need to be framed in terms of social analysis that can consider a body of texts in terms of their effects on power relations. In addition, if the ideology is primarily a representation, they can stay well "enacted" in the ways social act, and "inculcated" in the identities of social agents. Ideology can also have durability and stability that goes beyond individual text or body text. They can be associated with a discourse (as a representation), genre (reenactment), and with style (as inculcations). 
Textual analysis asks specific questions about social activities and texts (Fairclough, 2003:14). Fairclough (2003:15) also argued that imitations of textual analysis is the involvement of the text in the making meaning of causal effects, text and special effects the ideological text. However, textual analysis is limited. In addition, the involvement of texts in meaning-making, the causal effects of texts, and the specifically ideological effects of texts. None of these can be got at through textual analysis alone. To research, one needs to look at interpretations of texts as well as texts themselves, and more generally at how texts practically figure in particular areas of social life, which suggests that textual analysis is best framed within ethnography.

The method used is a critical discourse analysis of the model of Norman Fairclough started from the statement how the relationship between the text of macro, meso and, micro structure.

First, about macro structure. It consists of interpretation and explanation. The session of interpretation to reveal hidden relations strength and purpose. This stage is to specify whether 
the verbal cues in text contains certain assumptions or other hidden elements are not obvious at first sight (Fairclough, 1989:129).

Second, about meso structure. In General, the structure of meso acts as a bridge between micro and macro level and focuses on the context of the text that is perceived and how it was originally produced. CDA strives to reveal hidden relations in macro. Thus, the resulting text in the wider the context that contains the complex power relations, and the reader or listener to interpret it based on the norm their community.

Third, about micro structure. Micro structure includes description of lexical item and grammatical choice. Specifically, micro structure has three types of values in the text: experiential, relational, and expressive.

In other side, critical discourse analysis of Norman Fairclough's model does not only consist of text, but also the media environment that produces text, and macro social environment in which the media operate (Fairclough, 1992: 6364). 
Van Dijk's model has taken three element of critical discourse analysis. There macrostructures, superstructure, and microstructure of discourse as part of the concept of meaning of a discourse and have indicated how these global meanings are related with the meanings of sentences and sequences. Van Dijk's model summarized as follows;

Macrostructures may be expressed in the discourse itself by thematical (or topical) words or sentences (Van Dijk, 1980:27). Macrostructure focused on the theme of global emphasize on the meaning of discourse theme or topic. The meaning of discourse is not limited to the meaning of its sentences and words. Discourse also has "global" meanings, such as "topics" or "themes".

Macrostructure is a global meaning of discourse. It consists of thematic which seeks to look for the meaning behind the theme or topic are used in a news text. Thematic structure is the main part in textual analysis which is describe on how the writer shaping public mind or creating new perception. The topic commonly describes the global theme of a news text. Theme or 
topic is what is being spoken about. In order to analyze it can be seen from the unit analysis of this element is a whole text.

The superstructure specifically tends to be the particular discourse or organized by conventional schemata, such as define as an argument, a conversation or a news report. It tells us more on how parts of the text arranged into the whole news, for example, the setting of the introduction, substance, and conclusion. The part which is placed at the beginning, or which part are placed later, it will be organized as a shaper of important discourse. This level actually divided into three part such as, a headline, a lead, and a story. In story, consist of opening, content, and closing section.

According to Van Dijk (1988), formal superstructure deals with the form of the text. The focus element of its schema of the text. Schematic form is crucial part in textual analysis to understand the text. Schemata discusses about which part was hidden and was emphasized. How the way part of the text is schematic as a whole text. Even though, many variant of schema but news just have two general categories: summary and story. 
Summary formed from headline and lead. Whereas, story exhibits schematic functions. The story discusses about the situation and comments that should be appeared. Situation means the main event and setting to be described clearly, also comment from several figures which is sum up by the writer.

Schematic form is crucial part in textual analysis to understand the text. Schemata discusses about which part was hidden and was emphasized. How the way part of the text is schematic as a whole text.

Microstructure focuses by observing the semantics, syntactic, stylistic and rhetoric aspects. The use of words, propositions and rhetoric in certain media is not only seen as a means of communication but also as method of communication politic to influence the general premise, making support, strengthening legitimate and evacuate the enemy or opponent. Microstructure is a persuasive process when someone conveys the order and effective way to observe the next rhetorical.

Microstructure is a local meaning of texts. In this part, the researcher focuses on the structure of language (words, 
phrase, clause, sentences, and paragraph) within a text. Those are commonly included in semantics, syntactic, stylistic and rhetoric. The description is discussed in the following below:

a. Semantics

In this section, the analysis focuses on the meaning that is criticized in a news text. It can be observed in every paragraphs. There are five elements that will be analyzed which are setting, detail, mean, assumption and nominalization.

b. Syntactic

How the sentences are used in a text. The elements are form of sentence, coherence and pronoun that will be observed by analyse the proposition.

c. Stylistic

The main point here is style of the writers in using variant of language use in order to deliver message in news text. Style can be defined as the way of mind expression through particular taste of language which also exhibit speaker's personality and soul colour (Keraf, 
2010: 113). It can be identified by find out how the writer choose the appropriate one to use.

d. Rhetoric

The elements of rhetoric are graphic. Graphic highlighted the important point in a text. It can be identified by seek the use of bold, italic, underlined, bigger size, number, caption, picture, graphic, or table which are written differently. And then, metaphor is can be said as the main clue to understand the meaning of the text through society beliefs/daily utterance, proverb, or scripture in order to strength the central message. Further, refusal expression focuses on how writer hide certain information implicitly, can be signalled by the use of but or however.

\section{Students Activities:}

1. Texts are thing that is written and printed texts, such as transcripts of spoken communication, newspaper articles, 
or shopping list. Find a text in the form of the definition above.

2. Then analyze the text use macrostructure, superstructure and microstructure according to Van Dijk theory.

3. Then analyze the text use macro, meso and micro according to Fairclough theory. 
SOCIAL COGNITION

\section{Basic Competence:}

Students are able to analyze the social cognition use critical discourse analysis theory

\section{A. What is Social Cognition}

According to Van Dijk, the study of discourse is not enough to be based solely on text analysis, since the text is only the result of a production practice that must also be observed. Here it must be seen also how a text is produced, so that we gain a knowledge of why such text can be.

The production roses involve a process called social cognition. The text is formed in a practice of discourse, a practice of discourse. Here are two parts: a micro text that represents a topic of problems in the news, and a large element of social structure. Van Dijk created a bridge connecting a large element 
of social structure with a micro discourse element with a dimension called social cognition. On the one hand he shows how the process of text is produced by journalists / media, on the other hand he describes the values of society is spread and absorbed by the cognition of journalists and eventually used to make the news text (Eriyanto 2001: 222).

In discourse analysis there are three important things that affect production and discourse analysis namely: ideology, knowledge and discourse. Ideology affects discourse production. There is no discourse that is completely neutral or sterile from the speaker's or creator's ideology. Ideology is a belief system of both the collective trust of society and the typical group schemata, composed of categories that reflect the identity, social structure, and position of the group. Ideology is the basis of social attitudes. Knowledge is a proven belief (justified).

In Van Dijk's view, discourse analysis is not limited only to the structure of the text, because the structure of the discourse itself indicates or signifies a number of meanings, opinions, and ideologies. To uncover how the hidden meaning of the text, we 
need an analysis of cognition and the social context. The cognitive approach is based on the assumption that the text has no meaning, but the meaning is given by the language user, or rather the process of mental awareness of the language user. Therefore it takes a research on the representation of cognition and journalist strategy in producing a news. Because basically every text is generated through awareness, knowledge, prejudice, or certain knowledge of an event.

The analysis of social cognition is focused on the process of making news by journalists or communicators. Social cognition explains how journalists represent the values of belief or prejudice and knowledge as a strategy of forming text on specific events and reflected through the news. This analysis shows how individual journalists and communicators view and interpret events. Journalists use models to understand the events they are covering. This model incorporates opinions, attitudes, perspectives, and other information. According to van Dijk, there are several strategies undertaken by journalists, including: 


\section{Selection}

Selection is a complex strategy that shows how resources, events, information are selected by journalists to be featured in the news. The decision to use one news source, choose one news source over the other, prefer a usable interview. This selection process shows the position taken in the middle of the parties involved in an event.

2. Reproduction

If the selection strategy is related to what election is chosen to display, then reproduction is related to whether the information is copied, duplicated, or not used altogether by journalists. This is mainly related to news sources from news agencies or press releases.

3. Inference

This relates to how complex realities are understood and presented succinctly. In this process there are three interrelated things: omissions by summarizing 
information and some irrelevant information is omitted. Further generalizations where similar or similar information is used as general information. The latter constructs related to the combination of some facts or information so as to form the overall understanding.

\section{Local transformation}

If the inference is related to the question of how a complex event is simplified with a particular view, then the local transformation is related to how the event will be displayed.

\section{B. Discourse and Social Cognition}

The discourse in linguistic studies refers to the complete unity of language, which is generally greater than the sentence, whether delivered orally or in writing. Discourse analysis is not limited only to the structure of the text, because the structure of discourse itself shows or signifies a number of meanings, opinions, and ideologies. The cognitive approach is based on the 
assumption that the text has no meaning, but the meaning is given by the use of language or rather the process of mental consciousness of language practice.

As an example of social cognition here is talking about how cognition journalists write news. Journalist's work is basically a news reporter from various events and reports the opinion of the actors involved in the news. For example in an incident of the Century Bank scandal. Journalists must of course reconstruct the news, because at the time the incident happened he was not on the scene. The details, the victims, the events of the Century, the result, were all done by journalists with interviews of various parties involved ranging from perpetrators, figures involved, police, victims, chronology of the century case, and so on. How the Century case is displayed and how the parties involved are positioned in the text.

Journalists have the discretion to tell the events and also interpret the various actions that build the event, then the results of interpretation is used to build meaning that is conveyed to the audience. In this case the cognition of 
journalists influences how he defines himself but also defines others in his own perspective or point of view.

Therefore, according to Van Dijk, the discourse analysis must include how the reproduction of the beliefs on which the journalists should base a particular news text. There are several kinds of schemes or models that are described according to Van Dijk:

1. Person Schemas

This scheme illustrates how one person describes and views others. How an Islamic journalist, for example, sees and understands a Christian who is likely to affect the news to be written.

2. Self-Schemas

This scheme talks about how oneself is viewed, understood, and portrayed by someone.

3. Role Schemas

This scheme deals with how one views and describes the role and position one occupies in a society. 
4. Event Schema

This scheme relates to how someone confronts events. Then it is shown how your event, construed and interpreted.

\section{Students Activities:}

1. Social cognition explains how journalists represent the values of belief or prejudice and knowledge as a strategy of forming text on specific events and reflected through the news. Find local news, then analyze the social cognition based on journalist point of view.

2. Then analyze whether the journalist use the selection, reproduction, inference, local transformation strategy in social cognition discourse.

3. What is the significance in analyzing the social cognition of a text in discourse analysis. 
SOCIAL CONTEXT

\section{Basic Competence:}

Students are able to analyze the social context use critical discourse analysis theory

\section{A. What is Social Context}

Discourse is part of the discourse that develops in society, so to examine the text, need to do intertextual analysis by examining how the discourse about a thing produced in the community. An important point in this analysis is to show how shared meanings, social power are produced through the practice of discourse and legitimacy. According to van Dijk, in the analysis of this society there are two things to note namely the practice of power and access that affect the discourse. 


\section{Practice of power}

Van Dijk defines such power as possession possessed by a group (or its members), a group to control groups (or members) of other groups. This power is generally based on the ownership of valuable resources such as money, status, and knowledge. In addition to direct and physical control, power is also in the form of persuasive.

2. Access to affect the discourse

Van Dijk's discourse analysis gives great attention to access, how access is shared between groups within society. Elite groups have greater access than the nonpowerful groups. Therefore, those who are more powerful have a greater chance to influence audience awareness. Greater access not only provides an opportunity to control greater awareness of the audience, but also determines what topics and what content of the discourse can be disseminated and discussed to the public. For the analysis of social 
context is done through the study of intertextuality, namely linking a discourse with the related discourse that existed before and after. The linkage between text, social cognition and the social context reflects the tendency of a discourse. Discourse analysis conducted by van Dijk connects between text and context through social cognition of discourse makers. Media text discourse also requires analysis of intertextuality. This analysis is to know the relationship between text and practice of discourse. Intertextuality can combine the genres and discourses available in the discourse order for the production and consumption of texts. In addition, this analysis also looks at ways of transformation and text relation to one another (Fiske, 1982: 143-144).

One of the objectives of discourse analysis is to know the building of discourse that develops in society, the process of production and reproduction of a person or event described. About how meaning can be understood, then we must discuss 
the context of the news. The news context consists of two parts. First, is the social context. This system is closely related to the social and cultural conditions of society. The second is situational context. To view this situational context, we must look at the last conditions occurring in the social, cultural, and political life that accompany the event in this event.

According to Van Dijk, there are two important things in the analysis of social context: power and access. Power is a tool for one group in society that serves to control other groups. Usually this power arises when a group has valuable resources such as status, money, and position.

In the second point, the elite group as the owner of power has the ability to access all the potentials that tend to win the discourse. They have a vast opportunity to influence public awareness and can even define themes or topics to be shared with the public. 


\section{B. The Role of Context in Discourse Analysis}

According to Brown and Yule (1983), context is the environment or circumstances in which language is used. It can also be said that context is the text environment. In addition to the term context in terms of linguistic terms Indonesia also used the term environment, the same scope has different meanings because of different contexts.

There are several important contexts because they influence the production of discourse. First, discourse participants, whose background produces discourse, gender, age, education, social class, ethnicity, religion, in many ways describe discourse (for example: a person speaks with a particular view because he is educated or an adult). Second, certain social settings (place, time, position of speaker and listener and physical environment are useful contexts for understanding a discourse), for example, speaking in a different classroom by talking in the marketplace because the social situation and the rules surrounding it are different. 


\section{Concepts Relating to Context of Discourse}

Here are some concepts related to the context of discourse, among others:

1. Presupposition

According to Filmore (1981), in every conversation always used implicit or presupposive and explicit and illocutional levels of communication. For example, speech may be judged irrelevant or false not only in terms of the way the disclosure of events is misrepresented, but also on making the wrong way. Mistakes make prejudice have an effect in human speech. In other words, proper presuppositions can enhance the communicative value of a spoken utterance. The more precise presuppositions hypothesized, the higher the value of communication an utterance. In some ways, the meaning of discourse can be sought through presuppositions, but on the other hand there is a meaning that is not stated explicitly. The presupposition function is to help reduce the resistance 
response to the interpretation of an utterance. According to Leec (1981: 288) presupposes as a basis for the smoothness of communicative discourse. The statement of a presupposition will be the presupposition of the subsequent speech.

2. Implicatures

Implicatures concept first introduced by H. P. Grice (1975) to solve the problem of the meaning of language that cannot be resolved by the usual semantic theory. The implicature is used to account for what is suggested or what the speaker means as different from what is stated literally (Brown and Yule, 1983: 31).

3. Inference

Inference or withdrawal is said by Gumperz (1982) as a process of interpretation determined by the situation and context of the conversation. Thereby the listener assumes the willingness of the speaker, and with it the listener responds. Thus the inference of the conversation 
is not only determined by the words supporting the utterance, but also supported by context and situation. An idea embodied in the speaker's brain is in the form of sentences. If speakers are not good at composing a sentence then there will be misunderstandings.

\section{Deixis}

Deixis is a symptom of semantic contained in the word or construction that can only be interpreted taking into account the situation of reference with the talks. A word is deixed if the referent is switched or alternated, depending on who is the speaker and depends on the time and place in which the word is said. Deixis can be divided into three groups, namely deixis persona, deixis deixis of space and time.

a. Deixis persona

Deixis persona is an orientation for space and time deixis. In the category deixis persona, the criteria is the role of participants in the language event. The references pointing to by alternate persona depend 
on the role of the participant. The person who is talking gets a role called the first persona. When he does not speak again, and then becomes a listener then he turns into a second persona. People who are absent from the scene of the conversation (but not involved in the conversation) are called the third persona.

b. Deixis of Space

Not all lexeme space can be deixis and no lexeme space in the form of a noun. The new nomina can be locative if coupled with the preposition of space terms. All languages distinguish between "close to the speakers" for example here and that is not close to the speaker (including to the close to the listener) for example there. In many languages, as in the Indonesian language, it is also distinguished between "who is not close to the speaker and the hearer," for example, there. The space lexeme may be an adjective, adverbial or verb. 
c. Deixis of Time

Deixis time is disclosure (shaping) to the point of time or distance is seen from the time a phrase made (speaking events) is, now, compare that time, yesterday, this month, and so on. The forms in the grammatical categorization as "time warning" (as is the place dextical categorization). The two terms of motion can be related to time: we move through time (in which case time is considered silent) or time that moves toward us and passes through us. Space lexeme like front, back, long, short, used in the sense of time gives the impression as if time is a silent thing, while space lexeme like coming, then, arriving, approaching in the sense of time gives the impression that time is moving toward us.

\section{Students Activities :}

1. Explain the differences between social context and situational context! 
2. Explain the differences between discourse participants and social setting

3. Find a text, then analyze the social context. 


\section{MEDIA AND IDEOLOGY}

\section{Basic Competence:}

Students are able to understand the relation between the media and ideology

\section{A. Media}

According to Mc. Luhan (Wibawa, 1991: 7) the media are all message channels that can be used as a means of communication from one person to another that is not there. Romiszowski (Wibawa, 1991: 8) argues that the media is a messenger coming from a message source (which can be a person or an object) to the recipient of the message. Based on some opinions above can be concluded the media is a means or intermediary in conveying information from one person to another. 


\section{B. Ideology}

Van Dijk (2004: 5) holds that ideology is defined vaguely and generally has negative connotations. This is illustrated in the phrase that dichotomizes ideology with truth, so that ideology is automatically interpreted as a lie or an attempt to colonize the truth. The term ideology initially has no negative meaning as described above. This term is expressed at first by a French philosopher called Destutt de Tracy in the range of 1800 to van Dijk (2004), de Tracy reveals ideology term as a new discipline that examines the idea '. This term according to Freeden in van Dijk (2004) is still used neutrally in contemporary political science.

Similar to language, ideology is social. Ideology is the foundation for the social representation of a social group. Thus there is no individual or personal ideology. There is only the use of personal or individual ideology (Van Dijk, 2004: 8). This statement becomes very important for the research framework, because the news sampled by the research is not written by a 
journalist, but by some journalists, although still within the scope of one media.

Associated with ideology, van Dijk (2004: 13) limits ideology as a system of beliefs shared socially by the actors involved. It certainly refers to the existence of collective beliefs that must be understood as early stages in understanding ideology. Ideology is not only a social belief, but a fundamental or axiomatic character of social depiction of a social group, through certain social and mental (sosio-cognitive) behaviors.

Van Dijk (2004: 51-85) proposes the ideological discourse production strategy described in detail below.

(1) Actor description strategy, namely the description of the actor described in a discourse. The actor's portrayal will depend on the ideology of the discourse journalist.

(2) The strategy of submitting an authoritative argument (authority), namely the filing or mention of a recognized authority generally has authority or superiority in a particular area of expertise or in the matter of authority. 
(3) The burden strategy, namely the submission of an argument about the burden to be borne by a party on the actions taken by the other party.

(4) Categorization strategy, people tend to categorize social groups.

(5) Comparative strategy (comparison), namely the filing of an argument about equality or difference about something. It refers to characters, actions and events.

(6) Strategy submission of consensus that the claim about the agreement or the decision taken by certain parties proposed to reinforce an opinion or information.

(7) The strategy behind the rebuttal submission (counterfactuals), which is behind the statement or question posed to others so that the statement or the question was explained or answered by the other party.

(8) The disclaimer strategy, which is the submission of a phrase that denies or does not recognize the truth of a statement. Disclaimer is a blend of ideological-based strategy, self-image and negative depictions of others. 
(9) The strategy articulating euphemism, namely the use of statements that the smoothest the meaning of the word.

(10) Evidentially strategy, namely the submission of evidence to strengthen the opinion or knowledge owned by a party.

(11)The example and illustration strategy, one of the moves that is strong enough to argue, is by presenting a concrete example of a thing.

(12)The strategy of generalization (generalization), namely the submission of generalization of specific things.

(13) Hyperbole strategy (hyperbole), namely the submission of statements that overestimate the meaning.

(14) Implication strategy (implication), the speaker does not always have to reveal what is known or believed explicitly.

(15)The irony strategy (irony), which is the indirect indictment of allegations. 
(16) Lexicalization strategy, namely the mention of key words that form the basis of the concepts and beliefs of certain parties.

(17) Metaphorical strategy (metaphor), the use of figurative words that contain a stronger meaning than the actual word.

(18) National self-glorification, which is the filing of things that can arouse the sense of nationalism of the audience.

(19) Another negative portrayal strategy (negative other presentation), namely the mention of other parties with the designations that can bring a negative impression.

(20)The proposed strategy of normative expression (norm expression), namely the filing of a statement in the form of norms, prejudices, or whatever should be done based on the view of the norm.

(21)The number game strategy, namely the mention of the support figures as a quantitative fact support on a problem. 
(22)The polarization strategy, that is, the party's dichotomy, is intended to make the parties one contrast with the other.

(23) Populism is a claim submission involving everyone in a social group.

(24)The positive self-representation strategy is a positive self-representation to create a good impression on the other side and maintain the face of the party itself.

(25)The presupposition strategy is the proposition that invites others to think the way they want.

(26)The strategy of disguise (vagueness) is the mention of expressions that are not clearly defined.

(27)A victimization strategy, which is a description of the negative consequences that one party must receive due to the actions of the other.

\section{Media and Ideology}

In modern times, the media serves to disseminate a message to the public. Currently the media can also be used as a 
means to spread a certain ideology to the wider community. This media ideology can be observed through the content of the news, from which it will look where the thoughts of the media (also related to media workers) are directed.

Within the scope of the media, ideology is defined as a system of meanings that describes and defines reality making the values of justification for that reality. Ideology is not just to believe in reality. Ideology is also the basic way to define reality, so ideology is not only related to political issues.

For people who are engaged in politics, news and entertainment in the media can be a way to spread an ideology. They consider that the media is ideological, selling messages and certain views.

Basically there is no single ideology in the media. Most wellknown media promotes, often subtly and contradictively, the perspectives that support the composition of our social base and legitimize social institutions, removing attitudes and behaviors outside the mainstream. 
Sometimes the media defy the mainstream by criticizing contemporary social organizations and norms. But commercialization makes such criticism in trouble. The desire to seek popularity, wide distribution and profit has dulled the media's critical power. But there are still some media that consistently promote alternative ideologies, such as local newspapers or independent films, which are different from the mainstream. Only unfortunately the number of media like this and also the audience is very small.

\section{Ideology and Discourse Analysis}

Discourse as a form of communication act cannot be separated from a statement thought by the messenger (addressor). An oral and oral text besides containing discourse there is also an ideological charge, namely an understanding of an idea of the addressor. Therefore, a text can be analyzed its ideological content by examining it systematically and scientifically. The analysis of ideological content of discourse can 
be studied by systemic functional grammar and semantic micro approach.

An ideology conveyed by the addressor to the addressee is sometimes not necessarily accepted. Van Dijk (2004) says it could be that the ideology conveyed is a lie to a truth or a colonial attempt on the bourgeoisie. According to Geetrz (1973: 201) ideology is a belief that truth as a cultural system that contains elements of knowledge, belief norms, and values. This is why an ideology may arise because of the influence of other factors such as power. Furthermore ideology is considered true because of a compulsion to be believed by the addressee.

Can be exemplified in a book, novel, or short story. The ideology that the author attempts to convey through the existing language may be rejected by the reader even the general public, though sometimes his ideology will still be accepted by some readers because the point of view may be the same as the author.

Deeper still with the ideology of discourse according to Van Dijk that the ideology of a discourse born from a power and 
belief that should be proven truth. Furthermore the truth must be revealed and finally be believed by others.

Mandarani (2013) studies the critical discourse analysis to find out the ideology of discourse that developed by Kompas daily media about Joko Widodo and Fauzi Bowo reporting on Jakarta 2012 Election which leads to Joko Widodo and Fauzi Bowo imaging on Kompas daily media. This study uses the theory and method of critical discourse analysis van Dijk, in three dimensions / building that is text, social cognition, and social context.

The results showed that the ideology of daily news Kompas wants to show the description of Joko Widodo and Fauzi Bowo figure by carrying out a strategy of self-portrayal, comparison, polarization, metaphor, proof, irony, negative depictions of others, the strategy of filing denials and numbers games. This ideological discourse production strategy was used to describe the figure and strategy of Joko Widodo and Fauzi Bowo campaigns to form the image of the two candidates for governor through Kompas daily media. The ideology of discourse built by 
Kompas daily media leads to the discourse of media image formation on Joko Widodo and Fauzi Bowo figures. Joko Widodo is portrayed as a simple, charismatic, and populist figure of the governor of DKI Jakarta, because the discourse that was built on Joko Widodo leads to the humble figure of Joko Widodo, likes to plunge into the field so that he is closer to the people. Fauzi Bowo is portrayed as a bureaucratic, intellectual, and experienced Jakarta governor candidate, because the discourse that was built on Fauzi Bowo leads to the long-standing figure of Fauzi Bowo in politics, very well understood with the condition of Jakarta and highly educated. Joko Widodo and Fauzi Bowo is formed from the strategy of daily media ideology of Kompas that presents the theme of the campaign figure and strategy in its news which describes the positive image of the two candidates for governor.

Kompas daily media has a discourse ideology strategy that can illustrate the weakness of candidates with language that does not drop the candidate, so Kompas daily media tends to present a positive image to the figure of Joko Widodo and Fauzi 
Bowo in DKI Jakarta 2012 elections. The news of Kompas daily media is neutral without backdrop by certain interests. Kompas daily media coverage provides positive knowledge, insight and discourse about the candidates for governor and vice governor to the community of readers of Kompas daily newspaper and can be a source of consideration for voters in Jakarta 2012 regional election.

\section{Students Activities:}

1. What is the relationship between media and ideology?

2. Find a text of media, then analyze the ideology of the news media.

3. What is the ideology of Kompas in Jakarta election 


\section{REFERENCES}

2014. Understanding Media and Media Types. http://pengertianahli.id

Arifin, Bustanul and Abdul Rani. 2000. Principles of Discourse Analysis. Jakarta: Ministry of National Education.

Brown, Gillian dan Yule, George. 1984. Discaourse Analysis. Cambridge: Cambridge University Press.

Carrier, T. 2018. What Are the Different Types of Media Discourse? Conjecture Corporation. www.wisegeek.com

Carter, R. 1993. Introducing applied linguistics. Harlow: Penguin.

Cook, Guy. 1997. Discourse. Oxford: Oxford University Press

Cristianti, Tanti. 2012. A Little About Critical Discourse Analysis. tanticristianti.wordpress.com

Crystal, D. 1992. Introducing linguistics. Harlow: Penguin.

Dewadji, Narendra. 2009. The Relationship between the Theory of Social Cognition Teun A. Van Dijk as One of the Science of Discourse Analysis with Hermeneutics. www.narendradewadjikristy.blogspot.com

Dijk, Teun Van, T. 1985. Introduction: The Role of Discourse Analysis in Society. On van Dijk, T. (Ed.), Handbook of 
Discourse Analysis Volume 4: Discourse Analysis in Society. London: Academic Press.

Dijk, Teun Van, T. 2001. Principles of Critical Discourse Analysis. On Wetherell, M., Taylor, S., \& Yates, S.J. (Eds.), Discourse Theory and Practice: A Reader. London: SAGE Publications Ltd.

Dijk, Teun Van, T. 2004. Ideology: a Multidisciplinary Approach, London: Sage.

Dijk, Teun Van. 2015. "Critical Discourse Studies". Discourse of Society.

http://www.discourses.org/OldArticles/Critical\%20Disco urse\%20Studies.pdf.

DisTex. . Discourse and Social Cognition. wp.lancs.ac.uk

Eritanto. 2001. Discourse Analysis: Introduction to Media Text Analysis. Yogyakarta: LKiS.

Fairclough, N. 1985. Critical and Descriptive Goals in Discourse Analysis. Journal of Pragmatics

Fairclough, N. 1989. Language and Power. New York: Longman Group UK Limited.

Fairclough, N. 1995. Critical Discourse Analysis: The Critical Study of Language. Harlow-Essex: Longman Group Limited.

Fairclough, Norman. 1995. Critical Discourse Analysis. New York: Longman Group Limited. 
Febrianto, Mhd. 2017. Media and Discourse. www.kompasiana.com

Foucault, M. 1972. The Archeology of Knowledge and The Discourse on Language. London: Tavistock Publication.

Fowler, R. 1986. Linguistic Criticism. Oxford: Oxford University Press.

Fowler, R. 1991. Language in the News: Discourse and Ideology in the Press. London \& New York: Routledge.

Fowler, R. 1996. On Critical Linguistics. On Caldas-Coulthard, C.R. \& Coulthard, M. (Eds.), Texts and Practices: Reading in Critical Discourse Analysis London: Routledge.

Geertz, Clifford, 1973. The Interpretation of Cultures, Selected Essays New York: Basic Books Inc.

Halliday, M.A.K. 1978. Language as Social Semiotics. London: University Park Press.

Halliday, M.A.K. 1985/1994. An Introduction to Functional Grammar. London: Edward Arnold Publishers Ltd.

Halliday, M.A.K; Ruqaiya Hasan. 1994. Context and Text Language: Aspects of Language in Social Semiotic View. (The translation of Asruddin Barori Tou). Yogyakarta: UGM Press.

Jorgensen, Marianne W. dan Louise J. Philips. 2007. Discourse Analysis Theory and Methods. Yogyakarta: Pustaka Pelajar. 
Kusmanto, Joko. 2017. Text and Discourse: Critical Review of Terminology. https://jokokusmanto.blogspot.com

Kusuma, Balqis. 2015. Sociology of Communication: Media and Ideology. http://sekumpulantugasaya.blogspot.com

Lestari, Sri Cahya. . Van Dijk Discourse Analysis. www.naralestary.wordpress.com

Linguistik Id. 2016. How Relations Discourse and Ideology. www.linguistikid.com

Linguistik Id. 2016. Understanding Discourse and Discourse Analysis. http://www.linguistikid.com

Mandarani, V. 2013. Imaging of Joko Widodo and Fauzi Bowo in Kompas Daily Media on DKI Jakarta Election 2012. Thesis, Universitas Airlangga.

Maqdum, Mufatis. 2011. Critical Discourse Analysis. www.mufatismaqdum.wordpress.com

Matrikulasi. 2012. Critical Discourse Analysis. forum.detik.com

Mulyana. 2005. Discourse Study: Theory, Methods and Applications Principles of Discourse Analysis. Yogyakarta: Tiara Wacana

Nuraulyaulfacch. 2017. Context of Discourse. www.nuraulyaulfacch.wordpress.com

PMII Kebumen. 2010. Media Analysis. gerakanpmiikebumen.wordpress.com 
Prasetya, Ilham. 2017. Understanding Discourse, Types And Shape of Discourse, Discourse Wholeness, Discourse Example. www.ayoksinau.com

Putri, Allya Wardana. 2016. Discourse Analysis. www.sigeuliscampernik.wordpress.com

Renkema, J. 2004. Introduction to discourse studies. Amsterdam: John Benjamins Publishing.

Robbymilana. 2010. Media and Ideology. counteranalysis.wordpress.com

Rohman, Fathur. 2015. Type of Discourse Based on Media Submission (Oral and Writing) and Number of Speakers (Monologue, Dialogue and Polilog). http://fathurrohman9384.blogspot.com

Rumiati. 2013. Critical Discourse Analysis. http://analisiswacanakritis.blogspot.com

Said, Nasrullah. 2014. Understanding Discourse and Discourse Analysis. http://www.nasruldp.tk

Santoso, Anang. 2010. Discourse Theory: From the Descriptive Paradigm to the Critical Paradigm. Faculty of Literature, State University of Malang. http://studibahasakritis.blogspot.com

Susilana, Rudi. Riyana, Cepi. 2009. Media Pembelajaran: Hakikat, Pengembangan, Pemanfaatan, dan Penilaian. Bandung: CV Wacana Prima. 
Trisdiana, Yulia. 2015. Discourse Analysis Based on Teun A. van Dijk Theory. House of Knowledge. www.yullieatrissdhianna.blogspot.com

West, C. \& Zimmerman, D.H. 1985. Gender, Language, and Discourse. On van Dijk, T.A. (Ed.), Handbook of Discourse Analysis Volume 4: Discourse Analysis in Society. London: Academic Press.

Wiśniewski, Kamil. 2006. Discourse Analysis. Linguistics. www.anglozof.com

Wlliam. 2011. Discourse, Discourse Analysis, Context and Cotext. http://william-vampire.blogspot.com

Wodak, R. 1996. Disorders of Discourse. London \& New York: Longman. 


\section{ABOUT THE AUTHOR}



Vidya Mandarani's major is in English Literature and Linguistics, especially in Discourse Analysis and Applied Linguistics. She has Bachelor Degree in English Literature from Brawijaya University, graduated in 2008 and a master degree of literature and culture from Airlangga University in 2013. As a full time lecturer at Universitas Muhammadiyah Sidoarjo, she teaches the subjects related to English literature and linguistics. Instead of teaching, she has conducted some researches about Critical Discourse Analysis, and then published as articles in International Seminars and journals. Vidya has published two books about English Linguistics. Vidya is very enthusiast to develop the research in Linguistics related to the Indonesian cultures studies. Now, she focuses to the Media Discourse Analysis research. 